\title{
University-Level Design Engineering Challenges with Student Feedback
}

\author{
Jason Bazylak \\ University of Victoria \\ jbazylak@uvic.ca
}

\begin{abstract}
The Design Engineering Challenge Series is a set of design events organized by the University of Victoria Design Engineering Office to enhance the undergraduate student design experience. The first of the two events run in the series was the First Year Design Engineering Challenge. This event challenged first year engineering students to design and construct a microcontroller-directed electromagnetic model crane, in a single day. The second event had students from across campus working in interdisciplinary teams to design video games. Both events were extremely successful with follow up events planned for the next academic year.
\end{abstract}

\section{Introduction}

The Design Engineering Challenge (DEC) Series [1] is a set of design events organized by the Design Engineering Office at the University of Victoria. The primary objectives of these events are to:

- build student experience with design engineering;

- demonstrate that students are capable of tackling ambitious design projects, when motivated;

- publicizing engineering education to other students, members of the University community and the general public.

Two DEC events were developed and offered in the past year. The First Year Design Engineering Challenge (FYDEC) was run in September 2007

\author{
Peter Wild \\ University of Victoria \\ pwild@uvic.ca
}

and the Video Game Design Challenge was run in February 2008.

\section{First Year Design Engineering Challenge}

This hands-on engineering design project was undertaken by 173 first year students on their second day of classes in September, as part of their professional skills course, ENGR 020. The 2007 project [2] was to design and construct a microcontroller-directed electromagnetic model crane to remove "toxic scrap metal" from a "mine shaft". The event was designed and organised by the authors, with the assistance of two undergraduate students working full time on the project, one for four months and the second for two months.

Students were given one day (eight hours) to design and construct a solution, given a standard design kit. The standard design kit included PVC pipe and fittings, a Basic STAMP microcontroller and laptop, a custom relay board, various metal core shapes, magnetic wire, and other miscellaneous items. Teams were given one brief tutorial on programming the microcontroller, but no other direct lecturing. Instead, students were left to engineer solutions to this open-ended problem based, primarily, on their own ingenuity. Documentation was provided on microcontroller operation, crane structures and on electromagnet design. Students were also free to ask questions of the attending engineering faculty members and 12 graduate students teaching assistants. Teams were judged based on the performance of their design with respect to prescribed specifications: crane height, span, level of automation, and effectiveness of the electromagnet.

The event was high profile as it was held in a public location in the Student Union Building. The 
Faculty of Engineering received a great deal of positive attention due to the exciting atmosphere that surrounded the event. The success of this event led directly to the development of the second DEC event, the Video Game Design Challenge.

The documentation for the project has been made freely available on the project website [2]. Documents include: Project Introduction, Crane Design Tutorial, Electromagnet Design Tutorial, and the Basic STAMP Tutorial. Media recording the event, including still images and video, are also available.

\subsection{Student Feedback Survey}

Upon completion of the project, voluntary feedback was collected from the student participants using a commercial online survey tool [3].

The respondent rate was low at approximately $15 \%$, but of those who did respond the reaction was overwhelmingly positive.

Students were asked three questions. The first multipart question was intended to determine the value the students placed on the event. They were asked to rank, from Strongly Disagree (1) to Strongly Agree (5), their agreement with a series of statements on how they felt about the FYDEC. Summarized results can be found on Table 1 .

Table 1 - Student feedback on the value they placed on the FYDEC

\begin{tabular}{|l|c|}
\hline Statement & $\begin{array}{c}\text { Rating } \\
\text { Ave }\end{array}$ \\
\hline I had fun at the FYDEC. & 4.50 \\
\hline $\begin{array}{l}\text { I learned engineering related skills at } \\
\text { the FYDEC. }\end{array}$ & 4.21 \\
\hline $\begin{array}{l}\text { I learned non-engineering related } \\
\text { skills at the FYDEC. }\end{array}$ & 3.87 \\
\hline $\begin{array}{l}\text { I feel that having participated in the } \\
\text { FYDEC will help me in my future } \\
\text { academic career. }\end{array}$ & 3.33 \\
\hline $\begin{array}{l}\text { After the FYDEC, I have a better } \\
\text { understanding of what an engineer } \\
\text { does. }\end{array}$ & 3.76 \\
\hline $\begin{array}{l}\text { After the FYDEC, I have a better } \\
\text { understanding of what an Electrical } \\
\text { Engineer does. }\end{array}$ & 3.42 \\
\hline $\begin{array}{l}\text { After the FYDEC, I have a better } \\
\text { understanding of what a Mechanical } \\
\text { Engineer does. }\end{array}$ & 3.50 \\
\hline $\begin{array}{l}\text { After the FYDEC, I have a better } \\
\text { understanding of what a Software } \\
\text { or Computer Engineer does. }\end{array}$ & 3.75 \\
\hline
\end{tabular}

The FYDEC should be an annual

4.65

event.

The second question was intended to gather information for improvements that could be made to the event if it were run a second time. Students were asked to rank whether they felt they were supplied with too little (1), too much (1), or just the right amount (2) of a number of quantities. The results showed remarkable agreement that the students were given the right amount of support, time, and food (see Table 2).

Table 2 - Student feedback on the support, time, and food given to them

\begin{tabular}{|l|c|}
\hline Quantities & $\begin{array}{c}\text { Rating } \\
\text { Ave }\end{array}$ \\
\hline Documentation & 1.79 \\
\hline Engineering Consultant support & 1.92 \\
\hline Lecture time (STAMP Tutorial) & 1.61 \\
\hline Design and construction time & 1.70 \\
\hline Food & 1.58 \\
\hline
\end{tabular}

The final question asked for general feedback on the event and suggestions for improvements. Once again the comments were extremely positive. The only negative comments were related to the logistics of the event. Comments asking for better advertisement of the event and more follow up with an associated assignment. An example positive comment was:

"I would like to sincerely thank you for all your efforts arranging the [FYDEC]. This was a day full of excitement and fun! After my first taste of classes on the 5th, this event definitely gives me a reason to keep going."

-- First Year Engineering Student

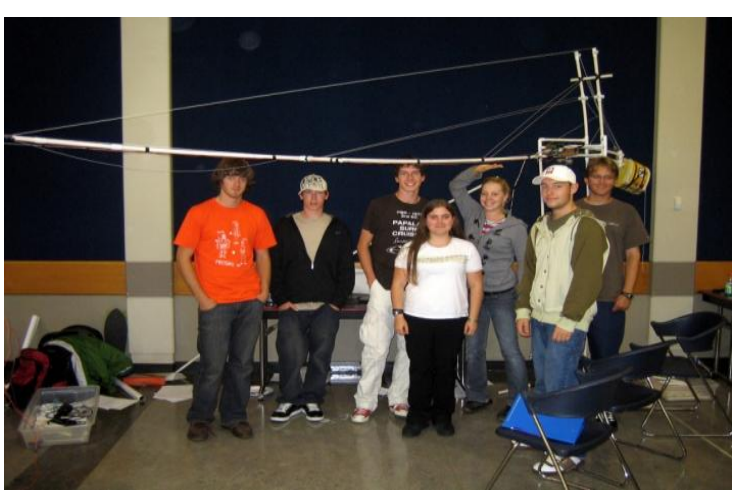

Figure 1 - 1 of 20 student design teams that participated in the 2007 FYDEC 


\section{Video Game \\ Design Challenge 2008}

\subsection{Lessons Learned}

As this was the first running on this event, care was taken to record issues that arose so that they can be addressed in future offerings of the event.

Computer hardware difficulties: After assembling into teams and sub-dividing into individual task forces, those responsible for the programming were asked to transport their Basic STAMP microcontrollers to a nearby computer lab. The intent was to conduct the Basic STAMP tutorial in an environment free from the distractions of the main design hall. Unfortunately, transport problems and hardware conflicts in the lab were numerous. This was the greatest obstacle encountered during the event.

Excessive teaching assistants: Judging from inactivity of many of the assistants for large portions of the event, 12 teaching assistants was excessive for 173 students.

Unnecessary barbeque: Following the event, a barbeque was offered for the students. The intent was to create a social environment for the students to continue their bonding. Unfortunately, after more than hours together, students were anxious to leave and the barbeque was poorly attended.

\section{Video Game Design Challenge}

The Video Game Design Challenge (VGDC) [4] was the second event in the Design Engineering Challenge (DEC) series. This challenge was extracurricular and was open to students outside the Faculty of Engineering. Competitors were formed into teams of three students and given one week, over the midterm break, to design and build a video game using a platform called GameMaker ${ }^{\mathrm{TM}}$ [5]. GameMaker ${ }^{\mathrm{TM}}$ is specifically designed to minimize the coding aspect of video game design and maximize the creative design aspect. An additional level of excitement was generated by supplying participants with the support needed to implement motion sensing technology (Nintendo Wii-motes) into their games.

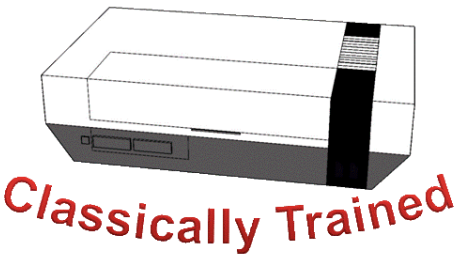

Figure 2 -Logo used to advertise the VGDC across campus

The primary source of competitors was the Faculty of Engineering; however there were also students from three other faculties with enough interest in video game design that they devoted their spring break to the project.

The event culminated in an exhibition in a public area, filled with projection gaming stations (see Figure 3). The general public was invited to attend and to play the student-designed games. The 13 games [6] that the students created were judged by a team that included an industry representative, a faculty representative and his 12 year old son, a group of local high school students, and the participants themselves.

The event also garnered great publicity for the Faculty of Engineering with multiple TV stations in attendance to interview the organizers and students and a radio spot on a local station.

The documentation for the project has been made freely available on the event website [4]. Documents include: Project Description, Registration Form, Evaluation Template, and Wiimote information. Media recording the event including still images and video are also available [7].

\subsection{Student Feedback Survey}

Upon completion of the project, voluntary feedback was collected from the student participants using a commercial online survey tool called Survey Monkey [3].

The respondent rate was high at approximately $56 \%$, and the reaction was overwhelmingly positive.

Students were asked five questions. The first multipart question was intended to determine the value the students placed on the event. They were asked to rank, from Strongly Disagree (1) to Strongly Agree (5), their agreement with a series of 
statements on how they felt about the VGDC. Summarized results can be found on Table 3.

Table 3 - Student feedback on the value they placed on the VGDC

\begin{tabular}{|l|c|}
\hline Statements & $\begin{array}{c}\text { Rating } \\
\text { Average }\end{array}$ \\
\hline I had fun at the VGDC. & 4.5 \\
\hline $\begin{array}{l}\text { If my availability were not an issue I } \\
\text { would participate in the VGDC again. }\end{array}$ & 4.75 \\
\hline $\begin{array}{l}\text { I expanded my knowledge of the } \\
\text { Design Process. }\end{array}$ & 4.3 \\
\hline I expanded my knowledge of Testing. & 3.75 \\
\hline I expanded my Programming Skills. & 3.15 \\
\hline $\begin{array}{l}\text { If a video game design course were } \\
\text { offered as an elective I would } \\
\text { seriously consider taking the course. }\end{array}$ & 4.4 \\
\hline $\begin{array}{l}\text { I have a better understanding what a } \\
\text { video game designer does. }\end{array}$ & 3.9 \\
\hline $\begin{array}{l}\text { The VGDC should be a regular } \\
\text { Faculty of Engineering event. }\end{array}$ & 4.85 \\
\hline
\end{tabular}

The second question was specifically directed towards participants from outside the Faculty of Engineering. $60 \%$ of these students responded that they felt welcome in the event despite being from outside the faculty. They also agreed that, through the event, they expanded their knowledge of the Faculty of Engineering.

The third question was intended to gather information for improvements that could be made to the event if it were run a second time. Students were asked to rank whether they felt they were supplied with too little (1), too much (1), or just the right amount (2) of a number of quantities. The results showed remarkable agreement that the students were given the right amount of support (see Table 4).

Table 4 - Student feedback level of support

\begin{tabular}{|l|c|}
\hline Quantities & Rating Average \\
\hline Formal lectures & 1.83 \\
\hline Formal tutorials & 2.00 \\
\hline Drop in help sessions & 2.12 \\
\hline Wiimote scripting sessions & 2.00 \\
\hline Online assistance & 2.06 \\
\hline
\end{tabular}

The fourth question was purely an administrative question and the results are not reported here.

The fifth and final question was an open question asking for general feedback on the event and any suggestions for improvements. Once again, the comments were extremely positive. The only negatives were related to the logistics of the exhibition day and requests for adjustments to the evaluation criteria. An example positive comment was:

"It was great! The level of support was exceptional and everyone was very supportive both in technical questions about GameMaker ${ }^{\mathrm{TM}}$ and also in regard to design questions in general."

--VGDC Student Participant

\subsection{Lessons Learned}

As this was the first running of this event, care was taken to record issues that arose so that they can be addressed in future offerings.

Team Selection: Teams were allowed to selfselect. This meant that some students were aware of their team long before those that asked to be placed in a team. This made it difficult to restrict students to working on their video game design only during the week allotted to the event.

Software Version: Two different versions of the GameMaker $^{\mathrm{TM}}$ software were allowed. It was decided that the Pro versus the Lite version did not offer any major advantages, however there was a perception among students that the Pro version provided an advantage.

Understaffed: The event was planned and run with a part time undergraduate student teaching assistant. This proved to be too little. While this deficiency did not show in the tutorial sections of the event, it was reflected in difficulties that were experienced in organizing the event, especially the final exhibition day.

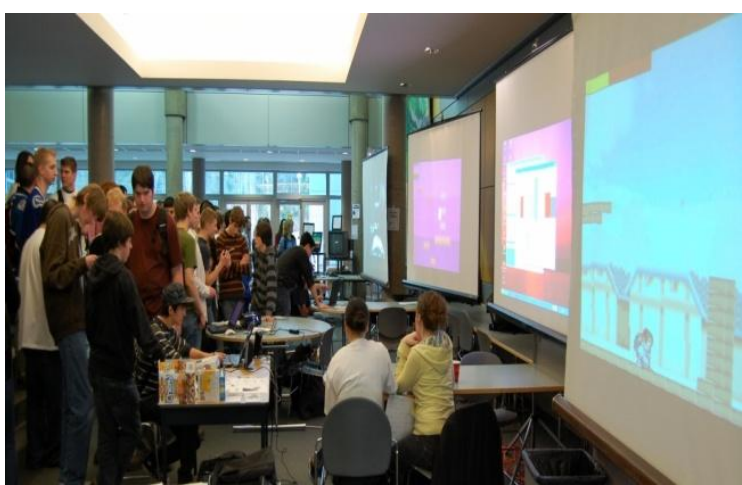

Figure 3 - The Video Game Design Challenge exhibition where 13 student-designed video games were on display for the public 


\section{Conclusions}

There were three goals in the creation of the DEC series and each of these goals has been met.

Build student experience with design engineering: Students who have participated in these events have increased their experience with open ended design problems. Additionally, their perception of their knowledge of the engineering profession and design work has been increased.

Demonstrate that students are capable of tackling ambitious design projects when motivated: In a single day FYDEC, participants designed and built automated electromagnetic cranes that exceeded 10 feet in height and span. VGDC participants worked in interdisciplinary teams to design and create an entire video game from scratch in a single week. In both events, student demonstrated to all those involved and the general public that, when properly motivated, they are capable of great things.

Publicizing engineering education to other students, members of the University of Victoria community, and the general public: Both events created a "buzz" around campus with a common question being, "When will the next design event happen?" The VGDC, in particular brought attention to engineering education through multiple $\mathrm{TV}$ and radio spots.

Both the FYDEC and the VGDC have been a success and the goal of the Design Engineering Office is to make them annual events. The second offering of the FYDEC for September 2008 is currently under development.

\section{References}

[1] "Design Engineering Challenge Series," <design.engr.uvic.ca/student-projects/dec/>, accessed June 27, 2008.
[2] "2007 Project," < design.engr.uvic.ca/studentprojects/dec/first-year/2007-project/>, accessed June 27, 2008.

[3] "Survey Monkey," <wwW.surveymonkey.com/>, accessed June 27, 2008.

[4] "Video Game Design Challenge 2008," <design.engr.uvic.ca/studentprojects/dec/vgdc/vgdc2008/>, accessed June 27, 2008.

[5] "YoYo Games - $\quad$ GameMaker," www.yoyogames.com/gamemaker, accessed June 27, 2008.

[6] "Video Game Design Challenge 2007 Games," $\leq$ design.engr.uvic.ca/studentprojects/dec/vgdc/vgdc2008/games/>, accessed June 27, 2008.

[7] "Video Game Design Challenge Media," <design.engr.uvic.ca/category/media/vgdc I>, accessed June 27, 2008. 